\title{
Effects of hyperbaric oxygen and nerve growth factor on the long-term neural behavior of neonatal rats with hypoxic ischemic brain damage ${ }^{1}$
}

\author{
Lixia Wei', Qing Ren", Yongjun Zhang III, Jiwen Wang ${ }^{\text {IV }}$
}

'MD, Department of Pediatrics, Liaocheng People's Hospital, Liaocheng, Shandong, China. Intellectual and scientific content of the study, manuscript writing.

"MM, Department of Pediatrics, Liaocheng People's Hospital, Liaocheng, Shandong, China. Intellectual and scientific content of the study, acquisition of data.

I'MM, Department of Pediatrics, Liaocheng People's Hospital, Liaocheng, Shandong, China. Statistical analysis.

IVMD, Department of Neurology, Shanghai Children's Medical Center, School of Medicine, Shanghai Jiaotong University, China. Design of the study, manuscript writing.

\begin{abstract}
Purpose: To evaluate the effects of HBO (Hyperbaric oxygen) and NGF (Nerve growth factor) on the long-term neural behavior of neonatal rats with HIBD (Neonatal hypoxic ischemic brain damage).

Methods: The HIBD model was produced by ligating the right common carotid artery of 7 days old SD (Sprague-Dawley) rats followed by $8 \% \mathrm{O} 2+92 \%$ N2 for $2 \mathrm{~h}$. Totally 40 rats were randomly divided into 5 groups including sham-operated group, HIBD control group, HBO treated group, NGF treated group and NGF + HBO treated group. The learning and memory ability of these rats was evaluated by Morris water maze at 30 days after birth, and sensory motor function was assessed by experiments of foot error and limb placement at 42 days after birth.

Results: The escape latency of HBO treated group, NGF treated group and NGF + HBO treated group was shorter than that of HIBD control group $(p<0.01)$ and longer than that of shamoperated group. The piercing indexes of 3 treated groups were higher than that of HIBD control group $(p<0.01)$.

Conclusion: Hyperbaric oxygen and nerve growth factor treatments may improve learning and memory ability and sensory motor function in neonatal rats after hypoxic ischemic brain damage.

Key words: Hyperbaric Oxygenation. Nerve Growth Factor. Hypoxia-Ischemia, Brain. Rats.
\end{abstract}




\section{Introduction}

HIBD (hypoxic ischemic brain damage), common in clinical, is mainly caused by neonatal hypoxia and asphyxia in the perinatal period $^{1-3}$. It has been shown that about 4 million newborns die worldwide each year, and $23 \%$ death of these newborns is caused by asphyxia ${ }^{4}$. In addition, neuron apoptosis, significant in the pathological process of HIBD, leads to the permanent neurological death or damage in newborns $^{3,5}$. Some achievements have been made in neonatal asphyxia recovery, but no important improvement has been gained in the prognosis of HIBD ${ }^{5}$. Because neuron apoptosis is the main cause of death, intervention of apoptosis cascade can decrease the neuron apoptosis'.

HBO (Hyperbaric oxygen) therapy is a treatment using the HBO to increase the supply of oxygen to wounds ${ }^{6}$, and this therapy has been used to treat neonatal disease for many years ${ }^{7}$. Additionally, HBO therapy helps to the protection and self-recovery of the affected brain ${ }^{8}$ and protects brain from ischemia injury by inhibition of mitochondrial apoptosis9. Moreover, HBO therapy has a neuroprotective effect in hypoxic-ischemic rats and has no side effects in HIBD neonatal rats $^{10-13}$. Furthermore, HBO therapy has neuroprotective effect by promoting brain cell proliferation ${ }^{14}$ or by anti-apoptosis and antioxidative stress ${ }^{15}$. NGF (Nerve growth factor), a neurotrophins, supports the differentiation and survival of neurons in the development of the brain ${ }^{16}$. It has been suggested that NGF can take neuroprotective, anti-apoptotic and antioxidative effect, and NGF may protect neuron from injury through these effects ${ }^{17}$. Moreover, NGF promotes peripheral nerve regeneration and reduces neural degeneration in rats ${ }^{18,19}$. It has been shown that the administration of exogenous NGF reduces severe neurological deficits in $\mathrm{HIBD}^{20}$. As above stated, many researchers have been performed about the roles of HBO and NGF in several aspects, but the effects of HBO and NGF on long-term neural behavior of neonatal rats have not been clearly explained.

In the present study, we used SD (Sprague-Dawley) newborn rats to construct HIBD models. Furthermore, the experiments of place navigation, space search, feet errors and limb placement were made to explore learning and memory ability, and sensory motor function in neonatal rats after HIBD. We aimed to study the effects of $\mathrm{HBO}$ and NGF on the long-term neural behavior of neonatal rats with HIBD.

\section{Methods}

\section{Preparation of HIBD models}

All procedures conform to the Principles of Laboratory Animal Care issued by the National Institues of Health, with local laws and regulations, and were approved by the local Animal Care and Use Committee.

A total of 40 SD newborn rats of both sexes, weighing $14.5 \pm 3.2 \mathrm{~g}$, aged 7 days old were selected and purchased from Medical Experimental Animal Center of Guangdong Province. The preparation process of HIBD models was followed as previously described ${ }^{21}$. SD rats were fixed in supine position, and routine disinfection of neck was performed. Subsequently, a $3 \mathrm{~mm}$ longitudinal incision was made, and the right common carotid artery was isolated by vessel forceps. The carotid artery was ligated by 0 sterile line, and then the incision was sewed up by $6 / 0$ disinfection disposable suture. The SD rats were then put in seal box with $8 \% \mathrm{O}_{2}$ after ischemia operation. Mixed gas including $8 \% \mathrm{O}_{2}$ and $92 \% \mathrm{~N}_{2}$ was added to the box with a speed of 1-2 L/min for $2 \mathrm{~h}$. The SD rats continued to be fed with lactation after ischemia-hypoxia. 


\section{Animal groups}

A total of 40 SD newborn rats were randomly divided into 5 groups, with 8 in each group, including sham-operated group, HIBD control group, HBO treated group, NGF treated group and NGF+HBO treated group. The right common carotid artery of shamoperated group rats was isolated but without ligation, hypoxia operation and intervention therapy. HIBD control group rats were fed regularly and were not be intervened after ischemia-hypoxia. HBO treated group rats were treated with $\mathrm{HBO}$ once (pure oxygen washing $5 \mathrm{~min}$ with the flow rate of $10 \mathrm{~L} /$ min, then 15-20 min compression with the flow rate of 5-8 L/ min to stay at $0.2 \mathrm{MPa} 30$ min and the average oxygen concentration at $85 \%-90 \%$ or above, and finally uniform decompression 20-30 $\mathrm{min}$ ) a day for 7 days after 15-30 minute of ischemia-hypoxia. NGF treated group rats were adopted with intraperitoneal injection of $0.5 \mu \mathrm{g}$ NGF (purchased from Xiamen North Road Biological Engineering Co., LTD) for each rat in 3 days after 15-30 minute of ischemiahypoxia. NGF+HBO treated group rats were adopted with intraperitoneal injection of $0.5 \mu \mathrm{g}$ NGF for each rat in 3 days after 1530 minute of ischemia-hypoxia, and then treated with HBO once a day for 7 days.

\section{Determination of Morris water maze behavior}

Morris water maze is a standard experiment that forced the experimental animals to learn to seek a hidden platform in water $^{22}$. The spatial learning memory ability is judged by analyzing learning memory ability for sense of space position and direction. Morris water maze experiment was performed in 5 groups at 30 days after birth.

Morris water maze is composed of circular pool, automatic image acquisition and processing system. The diameter, height and water depth of circular pool are $1300 \mathrm{~mm}$, $450 \mathrm{~mm}$ and $320 \mathrm{~mm}$ respectively. According to the position, the pool is divided into 4 quadrants (north, south, east and west), and these 4 quadrants are the start points of experiment. A platform, $1150 \mathrm{~mm}$ in diameter and $300 \mathrm{~mm}$ in height, hiding in $20 \mathrm{~mm}$ underwater, is placed in the middle of any quadrants. The platform and the wall are ivory-white, and the water is also ivory-white by adding fresh milk or milk power. The water temperature keeps in $23-25^{\circ} \mathrm{C}$ with thermostatic equipment. The position of the pool and the surrounding environment are always kept in the same. Automatic video recording and data collection are made by automatic image acquisition and processing system (Texas Instruments' TMS320C6416T, Germany).

\section{Place navigation experiment}

The place navigation experiment was used to judge learning and memory ability of rat in water maze by the test of the escape latency (the route map and time that rats seek and climb the platform $)^{23}$. The rat was put into the pool (without platform) swimming 2 minutes in the day before the experiment to make it familiar with the surroundings. The formal experiment went 5 days, 2 time quantum (morning and afternoon) a day, 4 times in each quantum, and the rats got into the water from 4 different points respectively. Then, the escape latency of 5 groups was recorded. If the experimental rat did not find the platform within 120 seconds, the rat was taken back to the platform and then 120 seconds were considered as escape latency. The interval between the two trainings is 60 seconds.

\section{Space search experiment}

The space search experiment was used to test the maintaining ability of spatial 
position memory after picking up the ability of seeking platform ${ }^{24}$. The platform was removed in the 6th day, and then the rats were put into the water at any one of the enter points. In addition, all rats must be in the same entry point, and the times that rats crossed the original platform within 2 minutes were piercing indexes.

\section{Test of sensory motor function}

The test of sensory motor function including the experiments of foot error and limb placement was performed in 5 groups of rats at 42 days after birth.

The experiments of foot error

The rats were put in the metal mesh $(500 \mathrm{~mm} \times 400 \mathrm{~mm}, 30 \mathrm{~mm} \times 30 \mathrm{~mm}$ per division, diameter $4 \mathrm{~mm}$ ) at 42 days after birth, and the times that the paws of fore and hind limbs fell down from the metal mesh were recorded. Because there were individual differences in the activity of the rats, the difference between the error counts of left and right sides were recorded.

\section{The experiments of limb placement}

The placement of paws of fore and hind limbs under different stimulus was recorded at 42 days after birth. If the placement of paws was correct and rapid, then 0 points was recorded. If the placement of paws was slow or not quite correct, then 1 points was recorded. If the rats did not place the paws in the metal mesh, then 2 points was recorded. Finally, the D-value (difference value) of every rat's score on both sides was recorded.

\section{Data processing}

The data were expressed by mean \pm standard deviation ( \pm s) and processed by SPSS $16.0(25)$. The data of piercing indexes, foot errors and limb placements were analyzed by one-way ANOVA (analysis of variance), and LSD (least significant difference) was used for comparison among groups. The data comparisons of escape latency in Morris water maze were performed by two-way ANOVA of repeated measurement data. $p<0.05$ was regarded as significant difference statistically.

\section{Results}

Determination of Morris water maze behavior

\section{Place navigation experiment}

Rats in each group spent a relatively long time finding the platform, and some rats found the platform without stopping in the $1^{\text {st }}$ round of training. Some rats could automatically seek the platform to rest since the beginning of the $2^{\text {nd }}$ round of training. The escape latency of rats in each group was gradually shortened with the increase of training times. The escape latency of $\mathrm{HBO}$ treated group, NGF treated group and NGF + HBO treated group was significantly shorter than that of HIBD control group $(P<0.01)$. The escape latency of HBO treated group ( $1^{\text {st }}$ and $\left.5^{\text {th }}, P<0.05\right)$, NGF treated group ( $1^{\text {st }}$ and $5^{\text {th }}, \mathrm{P}<0.01 ; 3^{\text {rd }}$ and $\left.4^{\text {th }}, \mathrm{P}<0.05\right)$ and $\mathrm{NGF}+$ HBO treated group $\left(1^{\text {st }}, 3^{\text {rd }}\right.$ and $5^{\text {th }}, \mathrm{P}<0.01$; $\left.4^{\text {th }}, \mathrm{P}<0.05\right)$ was longer than that of shamoperated group. There were no significantly statistical differences in the comparison of the escape latency of 3 treated groups ( $P$ $>0.05)$. The escape latency of rats in each group was gradually decreased with the increase of experiment days and training times, and there was a significantly statistical difference $(P<0.01)$. The comparison of the escape latency was shown in Table 1. 
Table 1 - Comparison of the escape latency $(n=8, x \pm s)$.

\begin{tabular}{|c|c|c|c|c|c|c|c|}
\hline Groups & $1^{\text {st }}$ day & $2^{\text {nd }}$ day & $3^{\text {rd day }}$ & $4^{\text {th }}$ day & $5^{\text {th }}$ day & F-value & P-value \\
\hline Sham-operated & $44.75 \pm 2.82$ & $32.25 \pm 2.12$ & $19.00 \pm 2.00$ & $15.50 \pm 2.45$ & $12.75 \pm 2.31$ & 258.70 & $<0.01$ \\
\hline HIBD control & $72.00 \pm 2.00 *$ & $64.88 \pm 2.23 *$ & $59.00 \pm 3.12 *$ & $50.00 \pm 2.83^{*}$ & $42.25 \pm 2.38 *$ & 171.81 & $<0.01$ \\
\hline HBO treated & $48.63 \pm 3.78 \Delta$ & $34.13 \pm 3.60$ & $21.30 \pm 2.12$ & $18.13 \pm 3.14$ & $15.63 \pm 2.33 \Delta$ & 161.30 & $<0.01$ \\
\hline NGF treated & $50.00 \pm 3.46 *$ & $35.25 \pm 3.28$ & $21.88 \pm 2.47 \Delta$ & $19.25 \pm 2.87 \Delta$ & $16.88 \pm 2.03 *$ & 187.22 & $<0.01$ \\
\hline $\begin{array}{l}\mathrm{NGF}+\mathrm{HBO} \\
\text { treated }\end{array}$ & $\begin{array}{c}49.38 \pm 3.50 * \\
\text { ¿ }\end{array}$ & $34.75 \pm 3.28$ & $22.38 \pm 2.26^{*}$ & $18.75 \pm 3.01 \Delta$ & $\begin{array}{c}16.38 \pm 2.07 * \\
\text { ¿ }\end{array}$ & 181.67 & $<0.01$ \\
\hline F-value & 89.66 & 173.30 & 391.75 & 202.40 & 236.53 & & \\
\hline P-value & $<0.01$ & $<0.0$ & $<0.01$ & $<0.001$ & $<0.01$ & & \\
\hline
\end{tabular}

\section{$\underline{\text { Space search experiment }}$}

The piercing indexes of $\mathrm{HBO}$ treated group, NGF treated group and NGF + HBO treated group were higher than that of HIBD control group $(P<0.01)$. The piercing indexes of 3 treated groups were lower than that of sham-operated group, and there was no statistical difference between these 3 treated groups and sham-operated group ( $P$ $>0.05)$. There were no significantly statistical differences in the comparison of the piercing index of $\mathrm{HBO}$ treated group, NGF treated group and $\mathrm{NGF}+\mathrm{HBO}$ treated group $(P$ $>0.05)$. The comparisons of the piercing indexes were shown in Table 2.

Table 2 - Comparison of the piercing index $(n=8, x+s)$.

\begin{tabular}{ccccccc} 
Groups & $\begin{array}{c}\text { Sham- } \\
\text { operated }\end{array}$ & $\begin{array}{c}\text { HIBD } \\
\text { control }\end{array}$ & $\begin{array}{c}\text { HBO } \\
\text { treated }\end{array}$ & $\begin{array}{c}\text { NGF } \\
\text { treated }\end{array}$ & $\begin{array}{c}\text { NGF+HBO } \\
\text { treated }\end{array}$ & F-value P-value \\
\hline
\end{tabular}

piercing index $8.13 \pm 0.64 * 5.00 \pm 0.767 .38 \pm 1.06 * 7.63 \pm 0.74 * 7.75 \pm 0.71 * 19.64<0.01$

Note: compared with HIBD control group, ${ }^{*} \mathrm{P}<0.01$.

Test of sensory motor function

The experiments of foot error

The left and right difference of foot error of $\mathrm{HBO}$ treated group, NGF treated group and NGF + HBO treated group was less than that of HIBD control group $(P<0.01)$. The left and right difference of feet error in 3 treated groups was more than that of sham-operated group, and there was no significantly statistical difference between these 3 treated groups and sham-operated group $(P>0.05)$. There were no significantly statistical differences in the comparison of the left and right difference of foot error in 3 treated groups $(P>0.05)$. The comparison of the left and right difference of foot error was shown in Table 3. 
Table 3 - Comparison of the left and right difference of foot error ( $(x \pm s)$.

\begin{tabular}{lcc}
\hline Groups & Numbers & D-value \\
\hline Sham-operated & 8 & $2.13 \pm 1.35^{*}$ \\
\hline HIBD control & 8 & $5.13 \pm 0.83$ \\
\hline HBO treated & 8 & $2.63 \pm 0.52^{*}$ \\
\hline NGF treated & 8 & $2.50 \pm 0.53^{*}$ \\
\hline NGF+HBO treated & 8 & $2.25 \pm 0.46^{*}$ \\
\hline F-value & & 39.05 \\
\hline P-value & \multicolumn{2}{c}{$<0.01$} \\
\hline Note: compared with HIBD control group, ${ }^{*} \mathrm{P}<0.01$.
\end{tabular}

The experiments of limb placement

The left and right difference of limb placement of $\mathrm{HBO}$ treated group, NGF treated group and NGF + HBO treated group was significantly less than that of HIBD control group $(P<0.01)$. The left and right difference of limb placement of HBO treated group $(P<0.01)$, NGF treated group $(P<$ $0.5)$ and NGF + HBO treated group $(P<0.05)$ was significantly more than that of shamoperated group. There was no significantly statistical difference in the comparison of the left and right difference of limb placement in 3 treated groups $(P>0.05)$. The comparison of the left and right difference of limb placement was shown in Table 4.

Table 4 - Comparison of the left and right difference of limb placement $(x \pm s)$.

\begin{tabular}{lcc}
\hline Groups & Numbers & D-value \\
\hline Sham-operated & 8 & $2.13 \pm 1.35^{*}$ \\
\hline HIBD control & 8 & $5.13 \pm 0.83$ \\
\hline HBO treated & 8 & $2.63 \pm 0.52^{*}$ \\
\hline NGF treated & 8 & $2.50 \pm 0.53^{*}$ \\
\hline NGF+HBO treated & 8 & $2.25 \pm 0.46^{*}$ \\
\hline F-value & & 39.05 \\
\hline P-value & $<0.01$ \\
\hline Note: compared with HIBD control group, ${ }^{*} \mathrm{P}<0.01$.
\end{tabular}

$\underline{H E}$ (hematoxylin and eosin) staining of brain tissues in five groups

HE staining of brain tissues was carried out for 5 groups, and the results were shown in Figure 1. The hippocampal pyramidal cells were multi-layered and neatly arranged, cellular outline was normal, and the nucleus was centered and nucleolus were distinct for the rats in sham-operated group (Figure 1A). For the rats in HIBD control group, the pathological changes of brain tissue mainly concentrated in the cerebral cortex and hippocampal CA1,CA3, the cerebral cortex became thinner, hippocampal pyramidal cells, layers of which were reduced, were irregular arranged and swollen, and the cell structure was fuzzy (Figure 1B). Compared with the HIBD control group, the pathological changes of brain tissue in $\mathrm{HBO}$ treated group, NGF treated group and NGF+HBO treated group were significantly reduced. There was no significant reduction for cerebral cortex and layers of hippocampal pyramidal cells, the cells arranged loosely, and a small number of neurons appeared pyknosis and karyorrhexis (Figure $1 \mathrm{C}-\mathrm{E}$ ).

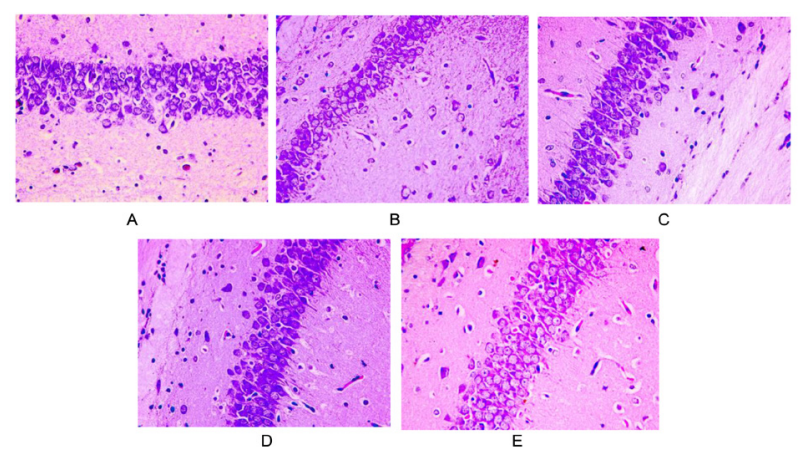

Figure 1 - HE staining of brain tissues (area CA1 of the hippocampus) for 5 groups. A, sham-operated group; B, HIBD control group; C, HBO treated group; $D, N G F$ treated group; $E, N G F+H B O$ treated group. $(\mathrm{HE} \times 400)$ 


\section{- Discussion}

Neonatal HIBD, caused by asphyxia in the perinatal period, creates permanent damage to nervous system in newborns or leads to the death in children5. In this study, the experiments of place navigation, space search, feet errors and limb placement in 5 groups were made to study the learning and memory ability, and sensory motor function in neonatal rats after HIBD. Our results showed that the escape latency of HBO treated group, NGF treated group and NGF + HBO treated group was shorter than that of HIBD control group. Furthermore, the piercing indexes in 3 treated groups were higher than that of HIBD control group. Moreover, the left and right difference of feet error and limb placement in 3 treated groups were less than that of HIBD control group. The results imply that HBO therapy and NGF treatment may improve neural behavior in HIBD.

HBO therapy may upregulate the process of improved synaptogenesis, dendritic changes and synaptic remodeling, and these processes occur as responses to brain injury ${ }^{26-28}$. Harch et al. ${ }^{29}$ indicated that HBO therapy might improve neural behavior by increasing the replication of neuronal and the differentiation of neuronal stem cells. In addition, HBO therapy can decrease cytotoxic edema of ipsilateral hippocampus and thus improve the learning and memory ability ${ }^{30}$. Furthermore, HBO can cause axon to sprout in models of peripheral nerve ${ }^{31}$. It has been shown that early HBO treatment improves the learning and memory ability by preventing nerve cell apoptosis ${ }^{32}$. Additionally, HBO therapy increases the density of contused hippocampus vascular, and then improves the spatial learning and memory ${ }^{29}$. Moreover, one study found that HBO therapy increased the expression of B-cell lymphoma 2 and boosted the activity of superoxide dismutase and glutathione content, and thus alleviated the apoptosis of hippocampus neural to improve the ability of learning and memory ${ }^{15}$. In our study, the results showed that HBO treatment could improve the learning and memory ability and sensory motor function in neonatal rats after HIBD. Therefore, our results are in accord with the former researches and indicate that HBO treatment can improve the neural behavior and the learning and memory ability.

Acioly et $a .^{33}$ indicated that NGF protected the newborn rat's neurons in HIBD stage. NGF can stimulate the differentiation, maintenance, survival and plasticity of neurons, and deficiency of NGF induces apoptosis of neurons ${ }^{34}$. In addition, augmentation of NGF enhances cholinergic neuronal markers and blockade of endogenous NGF impairs the retention of the spatialmemory ${ }^{35}$. Administration of NGF is a significant determinant for the recovery of neural behavior ${ }^{36}$. Furthermore, mature NGF regulates neuronal cell survival via the binding of TrkaA and p75NTR receptors, and preform NGF promotes neuronal apoptosis also via the binding of $p 75 N T^{37,38}$. NGF reduces the expression of caspase- 3 and p53 upregulated modulator of apoptosis, and then inhibits apoptosis of motor neurons after facial nerve injury of rats $^{39}$. Moreover, neuron apoptosis is significant in the pathological process of HIBD5. In our present study, NGF treatment also improved the learning and memory ability and sensory motor function in neonatal rats after HIBD. Therefore, our results are in line with the former researches and indicate that NGF treatment can improve neural behavior in HIBD.

\section{Conclusion}

Hyperbaric oxygen and nerve growth factor treatments may improve learning and memory ability and sensory motor function in neonatal rats after hypoxic ischemic brain damage.

\section{References}

1. Guo M-F, Yu J-Z, Ma C-G. Mechanisms related to neuron injury and death in cerebral hypoxic 
ischaemia. Folia Neuropathol. 2011;49(2):7887. PMID: 21845535.

2. Northington FJ, Chavez-Valdez R, Martin LJ. Neuronal cell death in neonatal hypoxiaischemia. Ann Neurol. 2011;69(5):743-58. doi: 10.1002/ana.22419.

3. Liu L, Johnson HL, Cousens S, Perin J, Scott S, Lawn JE, Rudan I, Campbell H, Cibulskis R, Li M. Global, regional, and national causes of child mortality: an updated systematic analysis for 2010 with time trends since 2000. Lancet. 2012;379(9832):2151-61. doi: 10.1016/S0140-6736(12)60560-1.

4. Chen $H$, Wei $K$, Zhou $C$, Yao $Y$, Yang $Y$, Fan X, Gao X, Liu X, Qian J, Wu B. Incidences of brain injuries in premature infants in seven large cities of China. Chinese J Clin Pediatr. 2011;29:1001-11.

5. Liu X-M, Feng Y, Li A-M. Effect of G-CSF and TPO on HIBD in neonatal rats. Asian Pac J Trop Med. 2015;8(2):132-6. doi: 10.1016/ S1995-7645(14)60303-5.

6. Kranke $\mathrm{P}$, Bennett $\mathrm{MH}$, Roeckl-Wiedmann I, Debus E. Hyperbaric oxygen therapy for chronic wounds. Cochrane Database Syst Rev. 2004;(2):CD004123. doi: 10.1002/14651858. CD004123.pub2.

7. Rudge F. Carbon monoxide poisoning in infants: treatment with hyperbaric oxygen. South Med J. 1993;86(3):334-7. PMID: 8451675.

8. Yang $Y$, Wang $X$, Yu X, Wang $X$, Xie M, Liu C. Hyperbaric oxygen induces endogenous neural stem cells to proliferate and differentiate in hypoxic-ischemic brain damage in neonatal rats. Undersea Hyperb Med. 2008 Mar-Apr;35(2):113-29. PMID: 18500076.

9. Li J-S, Zhang W, Kang Z-M, Ding S-J, Liu W-W, Zhang J, Guan Y-T, Sun X-J. Hyperbaric oxygen preconditioning reduces ischemiareperfusion injury by inhibition of apoptosis via mitochondrial pathway in rat brain. Neuroscience. 2009;159(4):1309-15. doi: 10.1016/j.neuroscience.2009.01.011.

10. Calvert JW, Zhou C, Nanda A, Zhang JH. Effect of hyperbaric oxygen on apoptosis in neonatal hypoxia-ischemia rat model. J Appl Physiol. 2003;95(5):2072-80. doi: 10.1152/ japplphysiol.00630.2003.

11. Veltkamp $R$, Siebing DA, Heiland $S$, Schoenffeldt-Varas P, Veltkamp C, Schwaninger M, Schwab S. Hyperbaric oxygen induces rapid protection against focal cerebral ischemia. Brain Res. 2005;1037(1):134-8. doi: 10.1016/j.brainres.2005.01.006.

12. Günther $A$, Küppers-Tiedt L, Schneider PM, Kunert I, Berrouschot J, Schneider D, Roßner $S$. Reduced infarct volume and differential effects on glial cell activation after hyperbaric oxygen treatment in rat permanent focal cerebral ischaemia. Eur J Neurosci. 2005;21(11):3189-94. doi: 10.1111/j.14609568.2005.04151.x.

13. Yang J-T, Chang C-N, Lee TH, Lin T-N, Hsu $\mathrm{J}-\mathrm{C}$, Hsu $\mathrm{Y}-\mathrm{H}, \mathrm{Wu} \mathrm{JH}$. Hyperbaric oxygen treatment decreases post-ischemic neurotrophin-3 mRNA down-regulation in the rat hippocampus. Neuroreport. 2001;12(16):3589-92. PMID: 11733717.

14. Hermann A, Maisel M, WegnerF, LiebauS, Kim DW, Gerlach M, Schwarz J, Kim KS, Storch A. Multipotent neural stem cells from the adult tegmentum with dopaminergic potential develop essential properties of functional neurons. Stem Cells. 2006;24(4):949-64. doi: 10.1634/stemcells.2005-0192.

15. Tian X, Zhang L, Wang J, Dai J, Shen S, Yang L, Huang $P$. The possible protective mechanism of Hyperbaric oxygen (HBO) in memory impairments induced by $A \beta 25-35$ in rats. Open Med. 2013;8(4):468-75.

16. Barde Y-A. Neurotrophins: a family of proteins supporting the survival of neurons. Prog Clin Biol Res. 1993;390:45-56. PMID: 7724649.

17. Yin X, Meng F, Wei W, Li A, Wang Y, Chai $Y$, Feng $Z$. Role of mouse nerve growth factor in neural recovery following hypoxicischemic brain damage. Int J Clin Exp Med. 2013;6(10):951. PMID: 24260602.

18. Tuszynski MH, Blesch A. Nerve growth factor: from animal models of cholinergic neuronal degeneration to gene therapy in Alzheimer's disease. Prog Brain Res. 2004;146:439-49. PMID: 14699979.

19. Sun $W$, Sun $C$, Lin $H$, Zhao $H$, Wang J, Ma $H$, Chen B, Xiao Z, Dai J. The effect of 
collagen-binding NGF- $\beta$ on the promotion of sciatic nerve regeneration in a rat sciatic nerve crush injury model. Biomaterials. 2009;30(27):4649-56. doi: 10.1016/j. biomaterials.2009.05.037.

20. Sofroniew MV, Howe CL, Mobley WC. Nerve growth factor signaling, neuroprotection, and neural repair. Annu Rev Neurosci. 2001;24(1):1217-81. doi: 10.1146/annurev. neuro.24.1.1217.

21. HuijinChen JZ, Zehan Z. Preparation of neonatal rats model with hypoxic ischemic brain damage. Shanghai Exp Anim Sci. 1999;19(3):159-60.

22. Morris RG. Morris water maze. Scholarpedia. 2008;3(8):6315.

23. Morris R, Garrud P, Rawlins J, O'Keefe J. Place navigation impaired in rats with hippocampal lesions. Nature. 1982;297(5868):681-3. PMID: 7088155.

24. Klahr D, Dunbar K. Dual space search during scientific reasoning. Cogn Sci. 1988;12(1):148.

25. Inc S. SPSS 16.0 for Windows. SPSS Inc, Chicago, IL. 2007. doi: 10.1006/ exnr.1996.6372.

26. Jørgensen OS, Hansen LI, Hoffman SW, Fülöp $Z$, Stein DG. Synaptic remodeling and free radical formation after brain contusion injury in the rat. Exp Neurol. 1997;144(2):326-38. doi: 10.1006/exnr.1996.6372.

27. Jones TA, Schallert T. Overgrowth and pruning of dendrites in adult rats recovering from neocortical damage. Brain Res. 1992;581(1):156-60. PMID: 1498666.

28. Bonomo S, Davidson J, Yu Y, Xia Y. Hyperbaric oxygen as a signal transducer: upregulation of platelet derived growth factor-beta receptor in the presence of $\mathrm{HBO} 2$ and PDGF. Undersea Hyperb Med. 1998;25(4):211. PMID: 9883488.

29. Harch PG, Kriedt C, Van Meter KW, Sutherland RJ. Hyperbaric oxygen therapy improves spatial learning and memory in a rat model of chronic traumatic brain injury. Brain Res. 2007;1174:120-9. doi: 10.1016/j. brainres.2007.06.105.

30. Liu S, Liu Y, Deng S, Guo A, Wang X, Shen $G$. Beneficial effects of hyperbaric oxygen on edema in rat hippocampus following traumatic brain injury. Exp Brain Res. 2015:17. doi: 10.1007/s00221-015-4405-7.

31. Haapaniemi T, Nylander G, Kanje M, Dahlin L. Hyperbaric oxygen treatment enhances regeneration of the rat sciatic nerve. Exp Neurol. 1998;149(2):433-8. doi: 10.1006/ exnr.1997.6745.

32. Peng Z, Xiao P, Guo H, Liu Q. Effect of early hyperbaric oxygen on neuronal apoptosis and learning and memory of cerebral ischemiareperfusion injury in rats. Zhong Nan Da Xue Xue Bao Yi Xue Ban. 2009 Jun;34(6):468-75. PMID: 19587426.

33. Acioly $\mathrm{MA}$, Carvalho $\mathrm{CH}$, Koerbel $\mathrm{A}$, Löwenheim $H$, Tatagiba $M$, Gharabaghi $A$. Intraoperative brainstem auditory evoked potential observations after trigeminocardiac reflex during cerebellopontine angle surgery. J Neurosurg Anesthesiol. 2010;22(4):347-53. doi: 10.1097/ANA.0b013e3181eac551.

34. Liu M, Wang S, Yao W, Zhang Z, Zhong X, Sha L, He M, Zheng Z, Wei M. Memantine improves spatial learning and memory impairments by regulating NGF signaling inAPP/PS1 transgenic mice. Neuroscience. 2014;273:141-51. doi: 10.1016/j.neuroscience.2014.05.011.

35. Conner JM, Franks KM, Titterness AK, Russell K, Merrill DA, Christie BR, Sejnowski TJ, Tuszynski MH. NGF is essential for hippocampal plasticity and learning. J Neurosci. 2009;29(35):10883-9. doi: 10.1523/JNEUROSCI.2594-09.2009.

36. Kemp SW, Webb AA, Dhaliwal S, Syed S, Walsh SK, Midha R. Dose and duration of nerve growth factor (NGF) administration determine the extent of behavioral recovery following peripheral nerve injury in the rat. Exp Neurol. 2011;229(2):460-70. doi: 10.1016/j.expneurol.2011.03.017.

37. Casaccia-Bonnefil P, Carter BD, Dobrowsky RT, Chao MV. Death of oligodendrocytes mediated by the interaction of nerve growth factor with its receptor p75. Nature. 1996;383(6602):716-9. doi: 10.1038/383716a0.

38. von Bartheld CS. Neurotrophins in the developing and regenerating visual system. Histol Histopathol. 1998;13(2):437-59. PMID: 
9589902.

39. Hui L, Yuan J, Ren Z, Jiang X. Nerve growth factor reduces apoptotic cell death in rat facial motor neurons after facial nerve injury. Neurosciences (Riyadh). 2015 Jan;20(1):65-8. PMID: 25630785.

\section{Correspondence:}

Jiwen Wang

Department of Neurology, Shanghai Children's Medical Center

School of Medicine, Shanghai Jiaotong University, No.1678 Dongfang Road, Pudong District

Shanghai, 200127, China

Phone: +86-021-38626161

wangjwendjj@hotmail.com
Received: Dec 05, 2016

Review: Feb 07, 2017

Accepted: March 10, 2017

Conflict of interest: none

Financial source: none

${ }^{1}$ Research performed at Laboratory Animal Center and Central laboratory, Liaocheng People's Hospital, Liaocheng, Shandong, China. 